\title{
Morfometría ovárica y expresión del ARN mensajero de hormona antimülleriana (AMH), receptor de FSH (FSHR) y factor nuclear kappa B (NFkB) en folículos en crecimiento de borregas expuestas prenatalmente a testosterona"
}

\author{
Ovarian morphometry and mRNA expression of antimüllerian hormone (AMH), follicle stimulating \\ hormone receptor (FSHR) and nuclear factor kappa B (NFkB) in growing follicles of female lambs \\ prenatally exposed to testosterone.
}

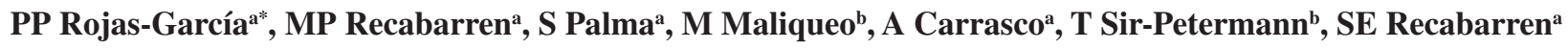 \\ 'Laboratorio de Fisiología y Endocrinología Animal, Departamento de Ciencias Pecuarias, \\ Facultad de Ciencias Veterinarias, Universidad de Concepción, Chillán, Chile.

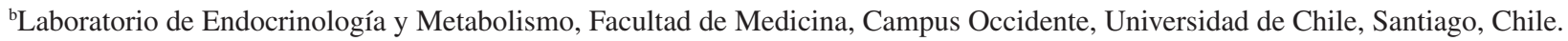

\section{SUMMARY}

\begin{abstract}
Antenatal exposure to testosterone (T) has a series of consequences on postnatal reproductive parameters in females of several animal species. In sheep born under this condition the ovaries are characterized by an increased number of growing follicles. If such disruptions are manifested early in life or involve changes in follicular recruitment and ovary paracrine environment, it remains unclear. This study addressed the impact of prenatal T on ovarian morphometry and the mRNA expression of ovarian anti-müllerian hormone (AMH), FSH receptor (FSHR) and nuclear factor kappa B (NFkB, a transcription factor for $\mathrm{AMH}$ ), factors that are involved in the growth and selection of the dominant follicle. At 4 weeks of age, female lambs born to dams treated with $30 \mathrm{mg}$ of $\mathrm{T}$ propionate twice weekly from day 30 to day 90 , followed by $40 \mathrm{mg}$ of $\mathrm{T}$ propionate from day 90 to day 120 of pregnancy ( $\mathrm{T}$ females), showed similar number of primordial, primary, secondary and antral follicles than control females (C females) born to dams treated with the vehicle. In the pool of secondary follicles $(<0.5 \mathrm{~mm})$ the expression of the FSHR was slightly higher in the T females, while AMH and NFkB expression were lower than $C$ females. Instead, the pool of small antral follicles (between 0.5 and $1 \mathrm{~mm}$ ) showed a higher expression of FSHR and a slight increase in $\mathrm{AMH}$ in $\mathrm{T}$ females, while NFkB expression remained lower than $\mathrm{C}$ females. These findings provide evidence that the prenatal exposure to $\mathrm{T}$ impacts the expression of key local factors governing the folliculogenesis before histological alterations occur.
\end{abstract}

Key words: fetal programming, sheep, follicles, testosterone, anti-müllerian hormone.

\section{RESUMEN}

La exposición prenatal a testosterona $(\mathrm{T})$ tiene consecuencias postnatales en parámetros reproductivos en hembras de varias especies. En ovejas, los ovarios presentan alteraciones en el mecanismo de selección folicular, caracterizándose por un aumento del número de folículos en crecimiento. No se sabe si este tipo de trastorno se manifiesta en etapas tempranas del desarrollo y si implica cambios en el reclutamiento folicular y en el ambiente paracrino del ovario. Este estudio abordó el impacto de la T prenatal en la morfología ovárica y en la expresión de hormona antimülleriana (AMH), receptor de FSH (FSHR) y factor nuclear kappa B (NFkB, un factor de transcripción de AMH). A las 4 semanas de edad, las hembras nacidas de madres tratadas con 30 mg de propionato de $\mathrm{T}$ dos veces por semana desde el día 30 a 90, seguido de 40 mg desde los 90 a 120 días de preñez (hembras-T), presentaron un número similar de folículos primordiales, primarios, secundarios y antrales que hembras control (hembras-C) nacidas de madres tratadas con el vehículo. En el pool de folículos secundarios la expresión del FSHR fue ligeramente mayor en las hembras-T, mientras que la expresión de AMH y NFkB fue menor. En cambio, en el pool de folículos antrales pequeños de hembras-T, la expresión del FHSR fue mayor, mientras que la expresión de NFkB se mantuvo baja. AMH fue levemente mayor. Estos resultados sugieren que la exposición prenatal a T modifica la expresión de factores locales que rigen la foliculogénesis.

Palabras clave: programación fetal, ovinos, reproducción en hembras, ovarios.

\section{INTRODUCCIÓN}

La exposición prenatal a un exceso de testosterona (EPT) es una condición anómala durante el desarrollo fetal, cuyas consecuencias se pueden manifestar con un

Aceptado: 30.05.2013.

\# Financiado por proyecto Fondecyt 1090031

* Casilla 537, Chillán, Chile; pedro.rojas@udec.cl retardo del crecimiento intrauterino y postnatal, obesidad, resistencia a la insulina y alteraciones en la neuroendocrinología reproductiva en hembras, que pueden derivar en infertilidad (Clarke y col 1977, Abbott y col 1998, Ozanne 2001, Birch y col 2003, Rosser y col 2003, Manikkam y col 2008, Recabarren y col $2005^{\mathrm{ab}}$ ). La EPT puede presentarse como característica clínica en el síndrome de ovario poliquístico (SOP) o en la hiperplasia adrenal congénita, condiciones que exponen a los 
fetos humanos en desarrollo a altos niveles circulantes de andrógenos.

En hembras ovinas, modelo animal de estudio en el cual se induce en forma experimental EPT, se han observado alteraciones neuroendocrinas, ováricas, genitales y conductuales desde el nacimiento hasta la edad adulta, algunas de las cuales semejan una masculinización. Las hembras ovinas EPT recién nacidas presentan menor peso corporal y aumento en la distancia anogenital, similar a la distancia que presentan los machos al nacer (Recabarren y col 2005a , Recabarren y col 2009). Durante el desarrollo prepuberal manifiestan un adelanto en el inicio de los ciclos estrales o pubertad precoz (Recabarren y col 2005 ), lo cual es signo de una masculinización reproductiva. Además, secretan una mayor cantidad de LH y estradiol en respuesta al test de análogo de GnRH, en comparación a las hembras nacidas de madres control (Recabarren y col 2005), lo que supone una mayor sensibilidad de la hipófisis y del ovario.

Histológicamente, existen hallazgos que indican un compromiso del ovario ante una EPT. En hembras ovinas EPT adultas, los ovarios presentan engrosamiento de la túnica albugínea y quistes de gran tamaño (Rojas-García y col 2006), similar a lo observado en ovarios de mujeres SOP. Otros estudios han demostrado que existe un mayor reclutamiento folicular (disminución de la proporción de folículos primordiales y aumento de folículos primarios) y un fenotipo poliquístico de los ovarios (Steckler y col 2005, Manikkam y col 2006, Forsdike y col 2007). En consecuencia, la testosterona en exceso puede alterar etapas tempranas de la foliculogénesis.

La hormona antimülleriana (AMH), también llamada MIS (substancia inhibitoria mülleriana) es una glicoproteína dimérica miembro de la superfamilia de los factores del crecimiento transformante beta (TGF $\beta$ s). La AMH es producida exclusivamente en el folículo ovárico en las células de la granulosa (Durlinger 2002 ). La AMH proveniente de los folículos preantrales y antrales pequeños puede actuar en 2 niveles: inhibiendo el reclutamiento inicial de los folículos primordiales a primarios y bloqueando el efecto estimulador de la FSH sobre el crecimiento de folículos preantrales y antrales pequeños, con lo cual se limita el número final de folículos antrales (Durlinger y col 2002 ${ }^{\mathrm{ab}}$, Carlsson y col 2006, Visser y col 2006). Se ha demostrado que la testosterona es capaz de inhibir la expresión de AMH en las células de la granulosa (Crisosto y col 2009) lo que provocaría un mayor paso de folículos primordiales y primarios hacia preantrales y antrales pequeños, aumentando la proporción de estos últimos en el ovario. A su vez, la FSH es capaz de estimular la transcripción del gen de la AMH en el ovario (Taieb y col 2011), probablemente a través del factor nuclear kappa B (NFkB, Lasala y col 2004), modulando de esta forma el crecimiento folicular.

Con estos antecedentes, proponemos que la EPT modifica la población de folículos y produce una dis- minución en la expresión a nivel de ARN mensajero (ARNm) de AMH y del factor de transcripción NFkB en los folículos de menor tamaño en el ovario ovino, en presencia de un aumento en la expresión del ARNm del receptor de FSH (FSHR). Para responder esta hipótesis, realizamos un análisis morfométrico de los ovarios y determinamos la expresión del ARNm de AMH, NFkB y de FSHR en folículos de hembras ovinas EPT de 4 semanas de edad.

\section{MATERIAL Y MÉTODOS}

\section{MANEJO GENERAL DE LAS MADRES Y CRÍAS}

Ovejas Suffolk adultas de fertilidad probada se cruzaron con machos en un régimen de sincronización de estros de acuerdo a lo descrito anteriormente (Recabarren y col 2005 $\left.{ }^{\text {ab }}\right)$. En breve, las hembras recibieron implantes intravaginales de progesterona Eazi-Breed (CIDR para oveja, Pfizer, número de catálogo sc-361819) por 7 días. $\mathrm{Al}$ séptimo día los implantes se retiraron y se le administró a cada oveja una dosis de $0,125 \mathrm{mg}$ de prostaglandina $\mathrm{F}_{2}$ a sintética D-Cloprostenol (Ovolute, Drag Pharma Invetec S.A., Santiago, Chile, número de catálogo 121678-1), siendo encastadas a las 48 horas siguientes. Con este procedimiento de sincronización de los estros, para monta dirigida, se aseguró una fecha de cruzamiento y de parto relativamente uniforme para el rebaño. Las ovejas preñadas se alimentaron en base a pradera, suplementadas con heno y alimento peletizado. Se dispuso de provisión de agua de bebida ad libitum. El manejo del parto y de los recién nacidos se realizó de acuerdo a lo descrito anteriormente (Recabarren y col 2009). Las crías se mantuvieron con sus madres estabuladas las 24 horas del día por las primeras 2 semanas. A las 4 semanas de edad, se seleccionaron al azar 5 hembras nacidas de madres control (hembras-C) y 9 hembras nacidas de madres EPT (hembras-T), ocupando solo hembras nacidas de partos únicos. Todos los procedimientos de manejo y de protocolos experimentales fueron aprobados por el Comité de Ética de la Facultad de Ciencias Veterinarias de la Universidad de Concepción, los cuales fueron desarrollados de acuerdo a la APS Guiding Principles of Care and Use of Animals (World Medical Association and American Physiological Society 2002).

\section{PROTOCOLO DE EXPOSICIÓN PRENATAL A TESTOSTERONA}

El protocolo de EPT que se ocupó corresponde al descrito por Recabarren y col (2008). Brevemente, las hembras preñadas se inyectaron intramuscularmente (i.m.) con $30 \mathrm{mg}$ de propionato de testosterona (T) (Steraloids, Inc. Newport, RI, Estados Unidos de América, número de catálogo 47000-000) diluida en aceite vegetal, dos veces por semana a partir de los 30 días y hasta los 90 días 
de preñez, seguido de $40 \mathrm{mg}$ T i.m. desde los 90 hasta los 120 días de preñez (término preñez $147 \pm 3$ días).

\section{OBTENCIÓN DE TEJIDO OVÁRICO}

A las 4 semanas de edad (etapa prepuberal temprana), las hembras-C y hembras-T, se pre-medicaron con 0,02 $\mathrm{mg} / \mathrm{Kg}$ de acepromacina $1 \%$ i.m. (Acedan inyectable, Holliday-Scott S.A. Argentina), 0,02 mg/Kg de sulfato de atropina $1 \%$ i.m. (Laboratorio Sanderson S.A., Santiago, Chile) y $5 \mathrm{mg} / \mathrm{Kg}$ intravenoso de ketamina $10 \%$ (Ilium Ketamil, Troy Laboratories Pty, Australia). Las hembras fueron intubadas para la administración de anestesia general. La inducción anestésica se llevó a cabo con isoflurano (FORANE, Baxter, Estados Unidos de América) liberado en oxígeno al sistema de respiración al 3,5\% y para la mantención anestésica se redujo al 3\%. Durante el período de anestesia el flujo de oxígeno fresco fue de $10 \mathrm{~mL} / \mathrm{Kg}$ por minuto. Una vez concluido el procedimiento quirúrgico el vaporizador fue apagado y sólo se insufló oxígeno a un volumen de 4 litros/minuto hasta que el reflejo deglutorio se recuperó procediendo a retirar el tubo endotraqueal. Mediante una ovariectomía bilateral se extrajeron los ovarios, los cuales se pesaron y uno de ellos se seccionó en 2 partes iguales. Una mitad se colocó en solución Bouin para los estudios morfométricos y la otra mitad en formalina para estudios inmunohistoquímicos posteriores. El otro ovario se colocó completo en medio de cultivo M-199 para separar y clasificar los folículos por tamaño.

\section{MORFOMETRÍA OVÁRICA}

Luego de la fijación, el trozo de ovario se embebió en parafina y se realizaron dos set de cortes seriados de $4 \mu \mathrm{m}$ de grosor, separados a una distancia de 400-480 $\mu \mathrm{m}$. Los cortes se tiñeron con hematoxilina-eosina. Los folículos se contabilizaron y clasificaron de acuerdo a los criterios de Lundy y col (1999) en: folículo primordial, ovocito rodeado de una sola capa de células de la granulosa, en que más del 50\% de las células son planas; folículo primario, una sola capa de células de la granulosa en que más del $50 \%$ son cuboidales; folículo secundario, más de una capa de células de la granulosa, pero sin antro discernible; folículo antral, más de cinco capas completas de células de la granulosa cuboidales con antro en desarrollo o completamente desarrollado. Se consideran folículos en crecimiento desde los folículos primarios en adelante. Cada folículo fue seguido en cada corte en el que apareció, con el objetivo de evitar doble conteo y fue contabilizado en la sección que contenía el nucleolo del ovocito. Cada 5 cortes se midió el área de la sección utilizando el programa de imágenes Leica Application Suite (Leica; Heidelberg, Alemania). Esta área se multiplicó por 5 para obtener el área correspondiente a las 5 secciones y luego se multiplicó por $4 \mu \mathrm{m}$ que es el grosor del corte. De esta forma se contabilizó el número total de folículos por $\mathrm{mm}^{3}$ de tejido, lo que se ajustó posteriormente al volumen total del ovario. El diámetro de cada folículo fue calculado como el promedio de dos mediciones del diámetro mayor en la sección que contenía el nucléolo del ovocito. Los folículos fueron clasificados como atrésicos si poseían más de tres células de la granulosa picnóticas, un ovocito deforme o una membrana discontinua, de acuerdo a lo descrito por Hay y col (1976).

\section{AISLAMIENTO DE FOLÍCULOS}

Los folículos se aislaron bajo lupa estereoscópica mediante el uso de pinzas y tijeras apropiadas. Una vez aislados se les midió el diámetro con un cáliper y se seleccionaron folículos de dos tamaños: secundarios o preantrales $(<0,5 \mathrm{~mm}$ de diámetro) y antrales pequeños (de 0,5 a $1 \mathrm{~mm}$ de diámetro). En base a la clasificación descrita, los folículos se agruparon y se depositaron en una solución de conservación de ARN (RNAlater ${ }^{\circledR}$ Ambion by Life Technologies, Santiago, Chile) y se almacenaron a $-20^{\circ} \mathrm{C}$ para los estudios posteriores de expresión génica. El grupo de folículos menores a $0,5 \mathrm{~mm}$ estuvo constituido por 28 folículos en el grupo de hembras-C y de 63 en el grupo de hembras-T. El grupo de folículos de 0,5 a $1 \mathrm{~mm}$ contenía 39 folículos de las hembras-C y 41 de las hembras-T. El número de folículos que conformaron cada grupo corresponde al número total de folículos que se pudo aislar y no necesariamente representan o expresan diferencias en el número total de folículos presentes en el ovario de las hembras ovinas en estudio.

\section{AISLAMIENTO DE ARN TOTAL, TRANSCRIPCIÓN INVERSA Y PCR EN TIEMPO REAL}

Los grupos de folículos almacenados a $-20^{\circ} \mathrm{C}$ en RNAlater ${ }^{\circledR}$ fueron homogeneizados utilizando el equipo Precellys 24 (Bertin Technology, Francia). La extracción del ARN total se realizó mediante el kit comercial RNeasy Mini Kit (Qiagen, Estados Unidos de América) siguiendo las recomendaciones del fabricante. La concentración de ARN total se determinó mediante un espectrofotómetro (Biofotómetro, Eppendorf®, Alemania) a $260 \mathrm{~nm}$. La calidad del ARN se evaluó de acuerdo a la relación 260/280 nm y su integridad, a través, de un gel de agarosa denaturante al 1\%. Se utilizó $1 \mu \mathrm{g}$ de ARN total en la transcripción inversa, previamente incubado con DNasa (Invitrogen by Life Technologies, Brasil, número de catálogo 18068-015), para evitar contaminación con $\mathrm{ADN}$ genómico. La transcripción inversa se realizó en un volumen final de $30 \mu \mathrm{L}$ de acuerdo a lo descrito anteriormente (Rojas-García y col 2010). Adicionalmente, para monitorear la ausencia de ADN genómico se analizaron muestras sin enzima transcriptasa inversa.

Previo a la realización del PCR en tiempo real, se procedió a estandarizar las reacciones de PCR para cada factor en relación a temperatura de anillamiento, concen- 
tración de partidores y concentración de $\mathrm{MgCl}_{2}$. Se utilizó $1 \mu \mathrm{L}$ de ADNc como templado para el PCR en tiempo real. La reacción de PCR se realizó según lo descrito anteriormente (Rojas-García y col 2010) utilizando el equipo RotorGen 6000 (Corbett, Australia). Las secuencias de partidores con su correspondiente temperatura de anillamiento se describen en el cuadro 1. Luego de 45 ciclos se procedió al análisis de la curva de disociación, para la verificación del producto de PCR amplificado. Para la cuantificación del ARNm se realizó una curva estándar con concentraciones conocidas, diseñada a partir del producto de PCR específicos para cada factor. La curva y las muestras de ADNc de cada factor se hicieron en duplicado. Como control interno de la transcripción inversa, el contenido de cada ARNm se normalizó con el gen constitutivo $\beta$-actina. Los datos del PCR en tiempo real se presentan como la razón entre el ARNm de cada gen y la expresión del gen $\beta$-actina.

\section{ANÁLISIS ESTADÍSTICO}

El número total de folículos y diámetro de los folículos (entre grupos y dentro de un mismo grupo) se analizaron utilizando el programa Prism GraphPad 4.0 mediante el test de $t$ no-pareado de Student o el test no-paramétrico de Mann-Whitney según corresponda. Los resultados de la morfometría se expresan como el promedio \pm error estándar (EE). Se consideró un valor de $\mathrm{P} \leq 0,05$ como estadísticamente significativo. La prevalencia de atresia folicular se expresó en porcentajes. Los valores de expresión del ARNm de los grupos de folículos de hembras-C $(<0,5 \mathrm{~mm}$ y 0,5 a $1 \mathrm{~mm}$ ) fueron utilizados como referencia, es decir constituían el 100\%. De acuerdo a esto, se determinó el porcentaje de variación en la expresión del grupo de folículos de las hembras-T con respecto a las hembras-C. Por tratarse de un grupo de folículos para hembras-C y hembras- $\mathrm{T}$ en las dos categorías descritas, no existe dispersión en los datos.

\section{RESULTADOS}

El peso promedio de las hembras al nacimiento $(4,020$ $\pm 0,44 \mathrm{Kg}$ en hembras-C y 4,039 $\pm 0,29 \mathrm{Kg}$ en hembrasT) y a las 4 semanas de edad $(10,21 \pm 0,98$ y $9,644 \pm$ $0,98 \mathrm{Kg}$, respectivamente) fue similar entre los grupos.

\section{MORFOMETRÍA OVÁRICA}

A las 4 semanas de edad el peso de los ovarios fue comparable en ambos grupos $(0,316 \pm 0,130 \mathrm{~g}$ en hembras-C contra $0,237 \pm 0,038 \mathrm{~g}$ en hembras-T). No todos los ovarios derivados del total de hembras utilizadas en el estudio $(n=14)$ se pudieron utilizar para el análisis morfométrico. En algunos de ellos, los cortes histológicos no eran apropiados para realizar los conteos, fundamentalmente por problemas de fijación del tejido. Debido a esto, se decidió utilizar solo aquellos ovarios cuyos cortes histológicos permitieran realizar recuentos y mediciones de manera segura. Por lo tanto, para esta parte del estudio se utilizaron ovarios provenientes de 4 hembras-C y de 5 hembras-T.

En ambos grupos de hembras se observó la presencia de folículos primordiales, primarios, secundarios y antrales (figura 1). No se observaron diferencias en el número de estos folículos entre hembras-C y hembras-T (figura 2). Tampoco se observaron diferencias en el porcentaje de atresia folicular (figura 3). El diámetro de las distintas poblaciones foliculares fue comparable entre ambos grupos (figura 4). Sin embargo, en las hembras-T los folículos antrales atrésicos fueron de mayor diámetro que los folículos sanos.

\section{EXPRESIÓN DEL ARNM DE AMH, NFKB Y RECEPTOR DE FSH}

Folículos secundarios o preantrales $(<0,5 \mathrm{~mm})$ : la expresión del ARNm de AMH en las hembras-T fue un

Cuadro 1. Detalle de las secuencias de partidores utilizados en el PCR en tiempo real.

Details of the primer sequences used in real time PCR.

\begin{tabular}{|c|c|c|c|c|}
\hline Gene & Partidor & $\begin{array}{l}\text { Anillamiento } \\
\quad\left({ }^{\circ} \mathrm{C}\right)\end{array}$ & $\begin{array}{l}\text { Largo del producto } \\
\quad \text { de PCR (pb) }\end{array}$ & Referencia \\
\hline$\beta$-actina & $\begin{array}{l}\text { F: 5'-TCAAGAACGAAAGTCGGAGG-3' } \\
\text { R: 5'-GGACATCTAAGGGCATCACA-3' }\end{array}$ & 55 & 178 & $\begin{array}{l}\text { Rojas-García y col } \\
2010\end{array}$ \\
\hline FSHR & $\begin{array}{l}\text { F: 5'-GAGAGCAAGGTGACAGAGATTCC-3' } \\
\text { R: 5'-CCTTTTGGAGAGACTGAATCTT-3' }\end{array}$ & 54 & 340 & $\begin{array}{l}\text { Rojas-García y col } \\
2010\end{array}$ \\
\hline AMH & $\begin{array}{l}\text { F: 5'-CTATGAGCAGGCCTTCCTGG-3' } \\
\text { R: 5'-CCTCCAGGTGCAGGACCACC-3' }\end{array}$ & 63 & 176 & Muruvi y col 2005 \\
\hline NFkB & $\begin{array}{l}\text { F: 5'-CCAAGACGGCTTCTACTACC-3' } \\
\text { R: 5'-TCCTTTCATCAGAGTGTGAGAG-3' }\end{array}$ & 60 & 148 & $\begin{array}{l}\mathrm{N}^{\mathrm{o}} \text { acceso al GenBank } \\
\text { EF121765.1 }\end{array}$ \\
\hline
\end{tabular}




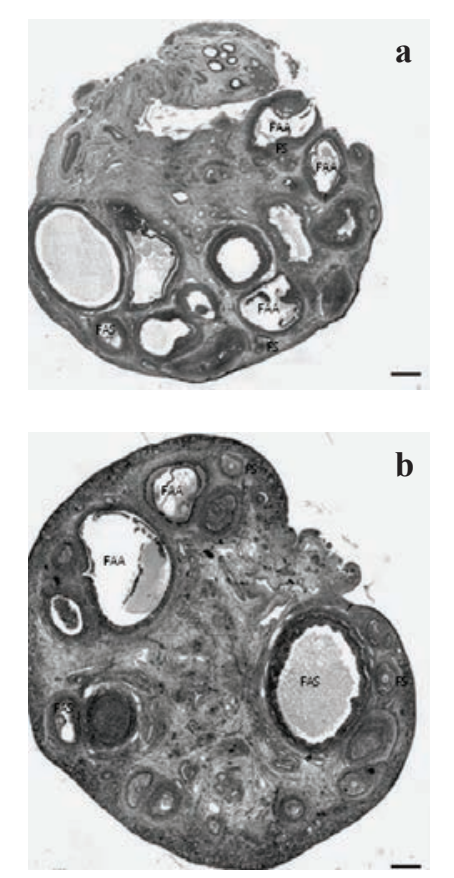

Figura 1. Fotomicrografía representativa de ovario de hembra ovina control (hembra-C, a) y expuesta prenatalmente a testosterona (hembra-T, b) a las 4 semanas de edad. FS: folículo secundario; FAS: folículo antral sano; FAA: folículo antral atrésico. Los folículos primordiales y primarios se ubican en la corteza ovárica. Barra $=200 \mu \mathrm{m}$.

Potomicrography representative of the ovine ovary in the control (C-female, a) and sheep with antenatal exposure to testosterone (T-female, b) sheep at 4 weeks of age. FS: secondary follicle; FAS: healthy antral follicle; FAA: atretic antral follicle. The primordial and primary follicles are located in the ovary cortex. Bar $=200 \mu \mathrm{m}$.

50\% menor que la expresión en hembras-C y la del factor NFkB en hembras-T fue un $73 \%$ menor que en hembras-C. La expresión del receptor de FSH fue levemente mayor $(7,7 \%)$ en las hembras-T ( 5).

Folículos antrales pequeños $(0,5-1,0 \mathrm{~mm})$ : en este grupo de folículos la expresión del ARNm de AMH fue levemente mayor en las hembras-T (2\%), mientras la baja expresión del factor NFkB se mantuvo en las hembras-T (67\%). Por el contrario, la expresión del ARNm del receptor de FSH fue mayor en hembras-T (73\%) que en las hembras-C (figura 5).

\section{DISCUSIÓN}

El presente estudio determinó que el número de folículos, el porcentaje de atresia y el diámetro folicular es similar entre hembras ovinas EPT y hembras control a las 4 semanas de edad. Sin embargo, la expresión del ARNm de AMH y de su factor de transcripción NFkB es menor en los folículos secundarios de hembras-T, en concordancia con nuestra hipótesis. En los folículos antrales pequeños, aún cuando la expresión del ARNm de NFkB se mantuvo baja, la expresión del ARNm de AMH se igualó entre los grupos. La mayor expresión del receptor de FSH en los folículos antrales pequeños de hembras-T, daría cuenta de una eventual mayor sensibilidad al efecto de la FSH, lo que explicaría el aumento en la expresión del ARNm de AMH observada en este grupo de folículos.

En estudios similares se observó que el porcentaje de folículos primordiales fue menor y el porcentaje de folículos en crecimiento (primarios y estadios posteriores) fue mayor en trozos de corteza ovárica provenientes de hembras ovinas EPT a los 8 meses de edad (Steckler y col 2005, Forsdike y col 2007). Además, se ha descrito la presencia de ovarios aumentados de tamaño y con un mayor número de folículos a las 3 y 5 semanas post parto (West y col 2001). Esta aparente discordancia de nuestros resultados con los descritos anteriormente, podría explicarse por las diferencias en las dosis y tiempo de exposición a testosterona aplicadas en el protocolo de androgenización y por las diferencias en la raza de las ovejas experimentales. En el presente estudio se inyectó una dosis de testosterona más baja y esa diferencia puede impactar en los resultados (Wood and Foster, 1998). De hecho, hembras ovinas EPT presentan un menor peso al nacimiento cuando se administra una dosis de $60 \mathrm{mg}$ de propionato de testosterona dos veces por semana entre los días 30 y 90 de preñez, lo cual no se manifiesta con las dosis utilizadas en el presente trabajo (Recabarren y col 2009).

Si bien, no se observaron cambios histológicos en la población de folículos, es posible especular que los cambios a nivel del ARNm actuarían como un indicador de las alteraciones que se desencadenarán en etapas posteriores del desarrollo. En hembras ovinas EPT adultas se demostró la presencia de una morfología ovárica multifolicular, incremento del reclutamiento folicular y persistencia folicular (Smith y col 2009, Mannikam y col 2006, Steckler y col 2007). Una probabilidad es que los efectos se observen en edades más avanzadas, cuando se acerquen a la pubertad. Estudios enfocados en dilucidar lo ocurrido en ese contexto de la edad reproductiva están aún en desarrollo en nuestro laboratorio.

Algunos de los factores claves que participan en la foliculogénesis son la AMH y la FSH. Se ha propuesto que la AMH producida por las células de la granulosa (Carlsson y col 2006), normalmente evita el reclutamiento de los folículos primordiales a primarios y a folículos antrales pequeños (Durlinger y col 2002 ${ }^{\mathrm{ab}}$, Carlsson y col 2006, Weenen y col 2004), regulando de esta forma el número de folículos preovulatorios. Sin embargo, esta regulación no se hizo evidente en el presente estudio, puesto que la población folicular no se modificó. No obstante, la menor expresión del ARNm de AMH en los folículos secundarios y su posterior alza en los folículos antrales pequeños, daría cuenta de los efectos de la $\mathrm{T}$ sobre la modulación del gen de AMH. La incubación de folículos ováricos de vacas con $\mathrm{T}$ in vitro disminuye la expresión del gen de AMH en células de la granulosa de folículos 
Folículos primordiales

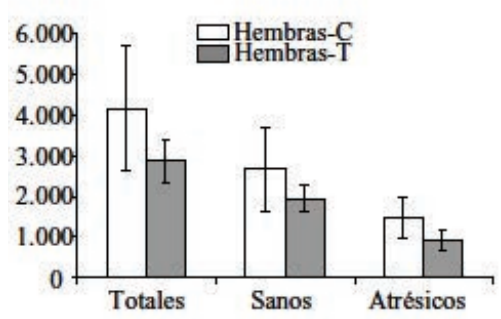

Folículos secundarios

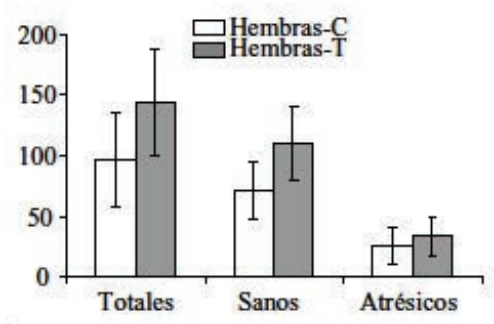

Foliculos primarios

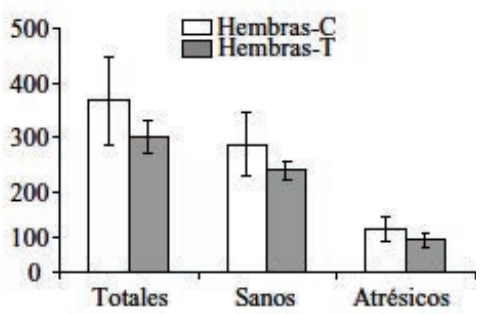

Foliculos atrésicos

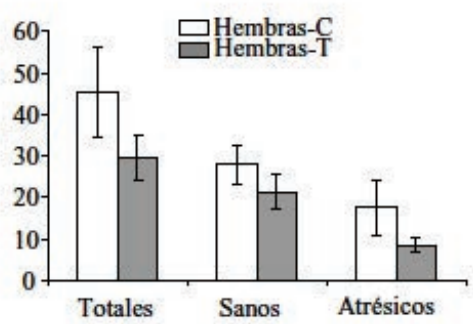

Figura 2. Número de folículos primordiales, primarios, secundarios y antrales de ovarios de hembras ovinas control (hembra-C, columnas blancas) y expuestas prenatalmente a testosterona (hembras-T, columnas negras) de 4 semanas de edad. Eje vertical indica número total calculado para ovario completo.

Number of primordial, primary, secondary and antral follicles of the control female (C-female, white columns) and those with antenatal exposure to testosterone (T-female, dark columns) at 4 weeks of age, calculated for the whole ovary.

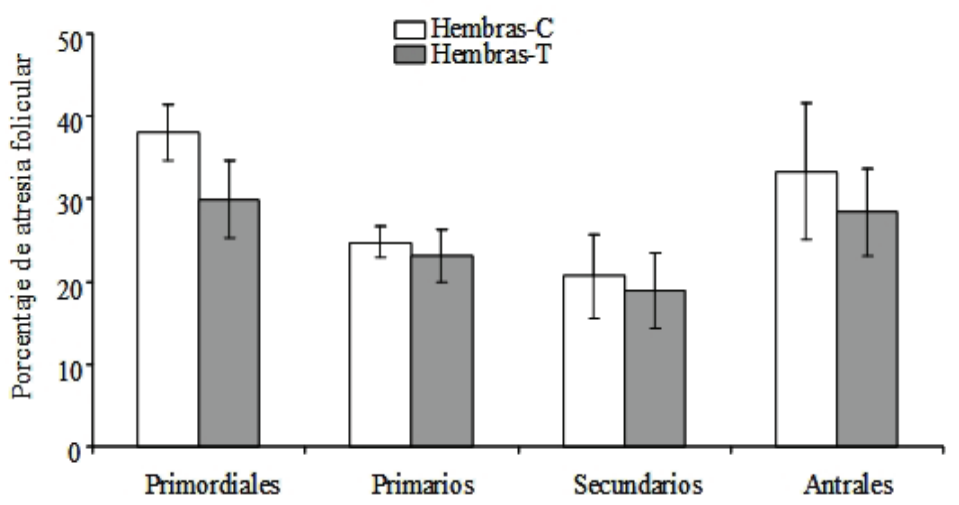

Figura 3. Prevalencia de atresia en folículos primordiales, primarios, secundarios y antrales en ovarios de hembras ovinas control (hembra-C, columnas blancas) y expuestas prenatalemente a testosterona (hembras-T, columnas negras) de 4 semanas de edad.

Prevalence of atresic in primordial, primary, secondary and antral follicles of control females (C-female, white columns) and those with antenatal exposure to testosterone (T-female, dark columns), at 4 weeks of age.

antrales pequeños, lo cual concuerda con los resultados obtenidos en los folículos secundarios de las hembras- $\mathrm{T}$ (Crisosto y col 2009). Los mecanismos por los cuales la $\mathrm{T}$ fetal reprograma la expresión de la AMH son desconocidos. Se ha observado que el ratón knockout para la AMH, muestra una disminución en el grupo de folículos primordiales, un aumento en el número de folículos preantrales y antrales, esto asociado a bajos niveles de FSH plasmática y aumento en la sensibilidad a FSH (Visser y col 2006). Por lo tanto, una posible explicación sería que la $\mathrm{T}$ regula el gen de $\mathrm{AMH}$, a través de las vías de señalización de la FSH.

La FSH estimula el crecimiento folicular en las últimas etapas del desarrollo folicular mediante la unión a su receptor (Driancourt y col 2001). Esto podría ser consecuencia de una mayor sensibilidad a la FSH, dada por 


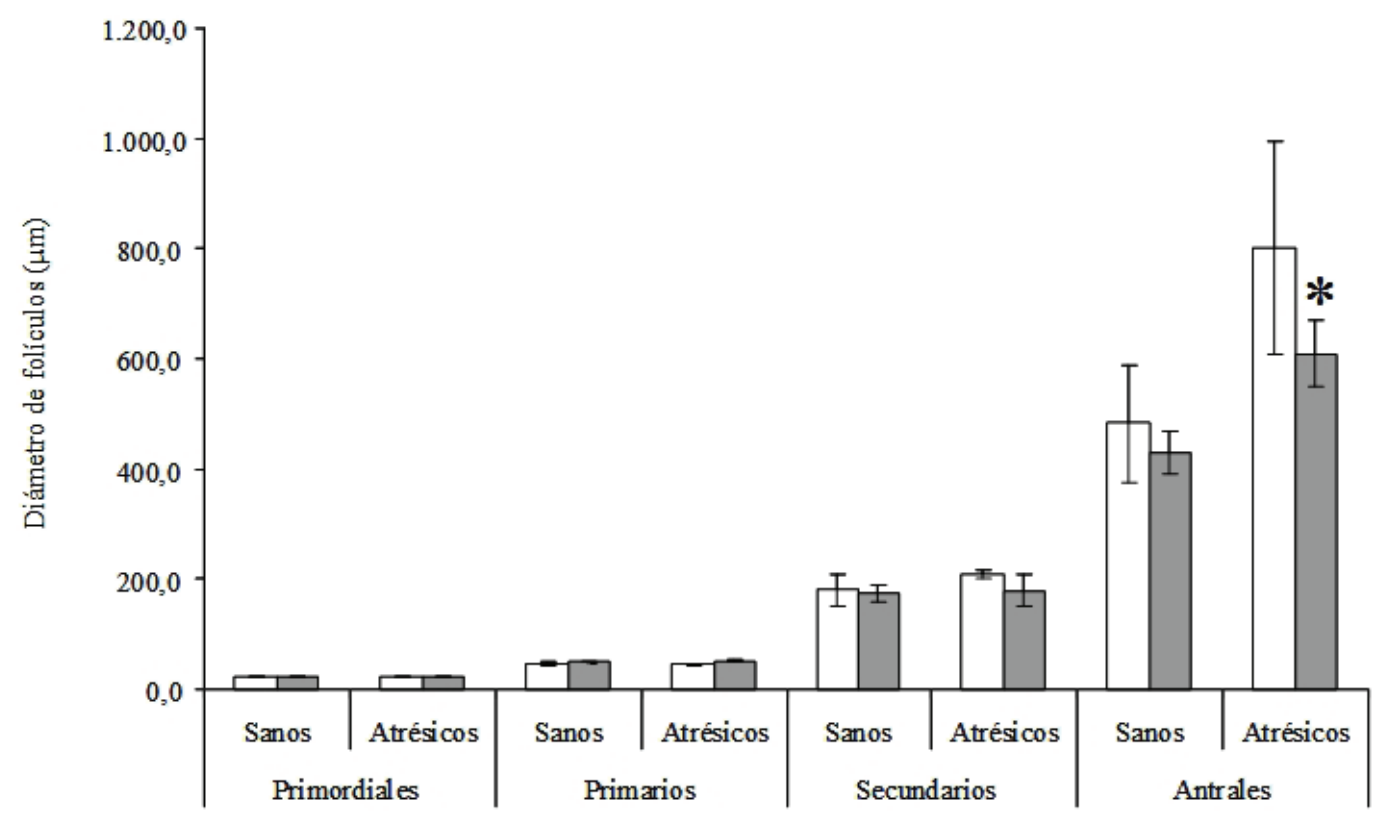

Figura 4. Diámetro de las distintas poblaciones foliculares de ovarios de hembras ovinas control (hembra-C, columnas blancas) y expuestas prenatalmente a testosterona (hembras-T, columnas negras) de 4 semanas de edad. El asterisco indica diferencias significativas entre los diámetros de folículos antrales sanos y atrésicos de las hembras- $\mathrm{T}(\mathrm{P}<0,05)$.

Diameter of the different follicular populations in ovaries of control females (C-female, white columns) and those with antenatal exposure to testosterone (T-female, dark columns), at 4 weeks of age. The asterisk indicates statistical differences in the follicular diameter of healthy and atretic follicles in T-females $(\mathrm{P}<0.05)$.

un aumento en la expresión de su receptor. La mayor sensibilidad debiera observarse en folículos en crecimiento, como los antrales pequeños. Concordante con esto, los folículos antrales pequeños de hembras-T presentaron una mayor expresión del receptor de FSH, lo que vislumbra un cambio molecular que tendrá impacto en la foliculogénesis. La falta de diferencias en el recuento de folículos en crecimiento, a pesar de este resultado puede ser debido a que los animales están en etapas prepuberales tempranas.

Nuestra hipótesis plantea que la $\mathrm{T}$ disminuye la expresión del gen de AMH en folículos preantrales pequeños, probablemente mediante modificaciones en los factores de transcripción. Una posibilidad estudiada en el presente trabajo incluye el NFkB, un factor de transcripción de AMH. El NFkB ha sido propuesto como un factor de transcripción que aumenta la expresión de AMH inducida por FSH, mediante la vía del AMPc-PKA en la célula de Sertoli (Lukas-Croisier y col 2003). Las células de Sertoli comparten el mismo origen que las células de la granulosa. Por lo tanto, esta sería la primera evidencia que demuestra que el NFkB se expresa en el ovario de oveja, probablemente a nivel de las células de la granulosa. De acuerdo a los resultados, la menor expresión de NFkB en los folículos de hembras-T de mayor tamaño no conduce a una mayor expresión del gen de AMH a pesar de un aumento en la expresión del ARNm del receptor de FSH. La disminución en la expresión del ARNm de NFkB podría hacerse evidente en los folículos antrales atrésicos de hembras-T, dado que el NFkB se ha reportado como un factor anti-apoptosis en las células de la granulosa (Xiao y col 2001, Wang y col 2002). De esta forma los folículos de hembras-T en estado más avanzado de crecimiento y por consiguiente de mayor diámetro estarían entrando en apoptosis.

Las hembras ovinas EPT tienen en común con las mujeres SOP los elevados niveles de andrógenos durante la preñez, lo que podría ser el origen de la desregulación en la síntesis y secreción de AMH observada en las hijas y madres SOP (Sir-Petermann y col 2002, Sir-Petermann y col 2006, Sir-Petermann y Crisosto 2007). Aunque en el presente estudio no se cuantificó la AMH circulante, el aumento en la expresión del ARNm de AMH en los folículos antrales pequeños en comparación a los secundarios en las hembras-T sugeriría que los niveles plasmáticos de AMH podrían ir en alza y semejar lo que ocurre en las mujeres SOP. El establecimiento de la metodología para la determinación de AMH plasmática en nuestro laboratorio ayudaría a evaluar dicha hipótesis.

En resumen, estos resultados sugieren que los trastornos derivados de la EPT se inician con cambios en la expresión a nivel del ARNm de factores que se expresan en etapas tempranas del crecimiento folicular. Estos factores estarían regulados por la dinámica de secreción de AMH, FSH y T lo cual definiría cuántos folículos inician su crecimiento y cuántos son seleccionados en etapas pre o postpuberales. 

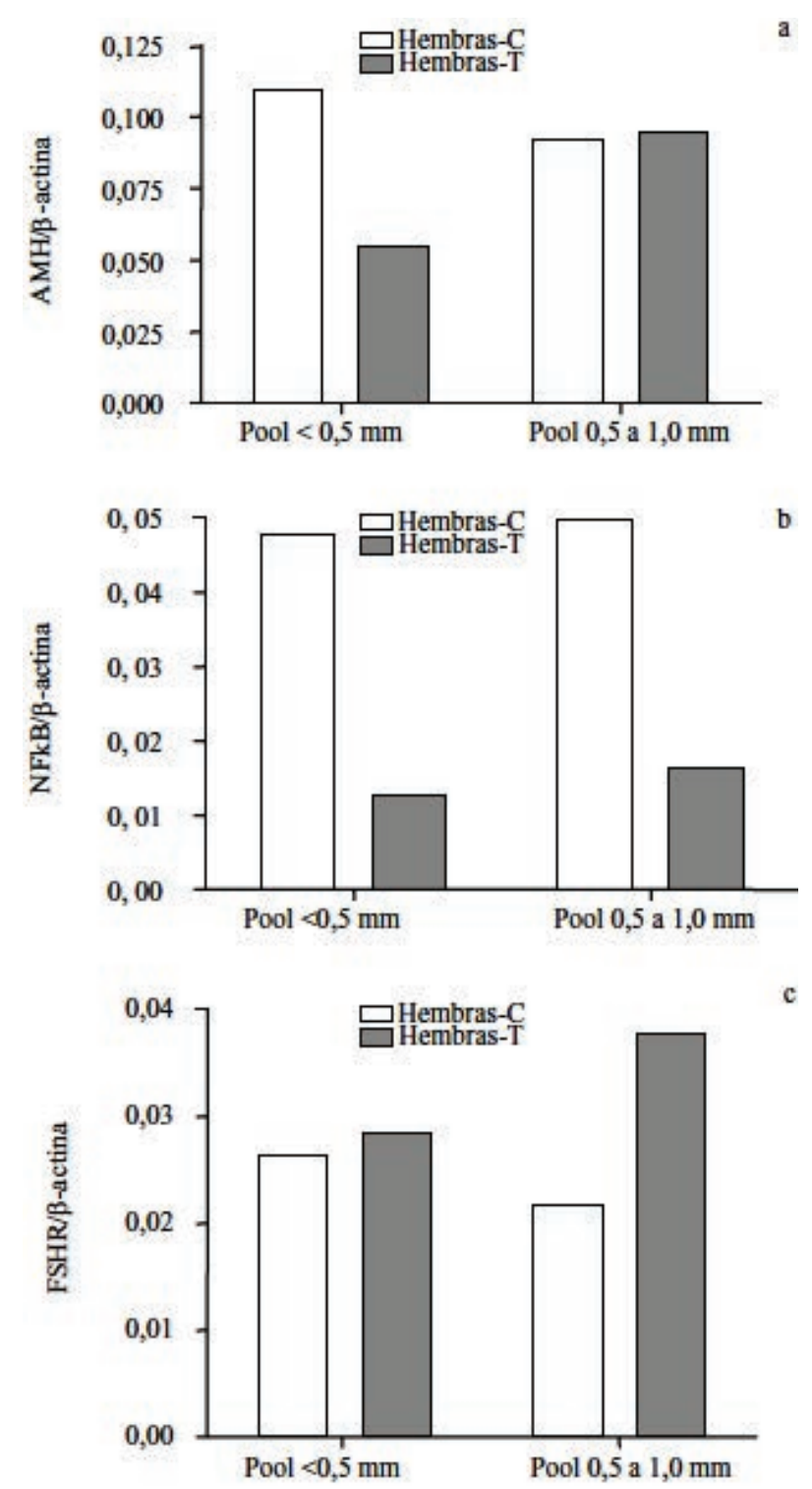

Figura 5. Expresión del ARNm de AMH (a), NFkB (b) y FSHR (c) en pooles de folículos de hembras ovinas control (hembras-C, columnas blancas) y expuestas prenatalmente a testosterona (hembras- $\mathrm{T}$, columnas negras) de 4 semanas de edad. La escala se muestra en base a la expresión del gen constitutivo. El análisis y las variaciones observadas (no existe barra de EE) se indican en el texto.

mRNA expression of AMH (a), NFkB (b) and FSHR (c) in follicular pools of control females (C-females, white columns) and those with antenatal exposure to testosterone (T-female, dark columns), at 4 weeks of age.

\section{AGRADECIMIENTOS}

Al Dr José Cox, Laboratorio de Biotecnología de la Reproducción, Facultad de Ciencias Veterinarias de la U de Concepción por el uso de la sala de cirugía y de microscopía para colección de ovarios y aislación de folículos. Al Señor Heriberto Tobar, por su colaboración en la obtención de folículos ovári- cos. Al DAAD (Alemania) por la donación del biofotómetro para la cuantificación de ARN. A la empresa BIOSCAN (Santiago de Chile) for facilitarnos el equipo Precellys. Este trabajo fue financiado por Proyecto Fondecyt 1090031.

\section{REFERENCIAS}

Abbott DH, DA Dumesic, JR Eisner, RJ Colman, JW Kemnitz. 1998. Insights into the development of polycystic ovary syndrome (PCOS) from studies of prenatally androgenized female Rhesus monkeys. Trends Endocrinol Metab 9, 62-67.

Birch RA, V Padmanabhan, DL Foster, JE Robinson. 2003. Prenatal programming of reproductive neuroendocrine function: fetal androgen exposure produces progressive disruption of reproductive cycles in sheep. Endocrinology 144, 1426-1434.

Carlsson IB, JE Scott, JA Visser, O Ritvos, APN Themmen, O Hovatta. 2006. Anti-müllerian hormone inhibits initiation of growth of human primordial ovarian follicles in vitro. Human Reprod 21, 2223-2227.

Clarke IJ, RJ Scaramuzzi, RV Short. 1977. Ovulation in prenatal androgenized ewes. J Endocrinol 73, 385-389.

Crisosto N, T Sir-Petermann, M Greiner, M Maliqueo, M Moreno, P Aedo, HE Lara. 2009. Testosterone-induced downregulation of anti-Müllerian hormone expression in granulosa cells from small bovine follicles. Endocrine 36, 339-345.

Driancourt MA. 2001. Regulation of ovarian follicular dynamics in farm animals. Implications for manipulation of reproduction. Theriogenology 55, 1211-1239.

Durlinger AL, JA Visser, AP Themmen. 2002 ${ }^{\mathrm{a}}$. Regulation of ovarian function: the role of antimüllerian hormone. Reproduction 124, 601-609.

Durlinger AL, MJ Gruijters, P Kramer, B Karels, HA Ingraham, MW Nachtigal, JT Uilenbroek, JA Grootegoed, AP Themmen. 2002 . Anti-müllerian hormone inhibits initiation of primordial follicle growth in the mouse ovary. Endocrinology 143, 1076-1084.

Forsdike RA, K Hardy, L Bull, J Stark, LJ Webber, S Stubbs, JE Robinson, S Franks. 2007. Disordered follicle development in ovaries of prenatally androgenized ewes. $J$ Endocrinol 192, 421-428.

Hay MR, DG Cran, RM Moor. 1976. Structural changes occurring during atresia in sheep ovarian follicles. Cell Tissue Res 169, 515-529.

Lasala C, C Carré-Eusèbe, JY Picard, R Rey. 2004. Subcellular and molecular mechanisms regulating anti-Müllerian hormone gene expression in mammalian and nonmammalian Species. Dna Cell Biology 23, 572-585.

Lukas-Croisier C, C Lasala, J Nicaud, P Bedecarras, TR Kumar, M Dutertre, MM Matzuk, JY Picard, N Josso, R Rey. 2003. Follicle stimulating hormone increases testicular anti-müllerian hormone (AMH) production through Sertoli cell proliferation and a nonclassical cyclic adenosine 5'-monophosphate-mediated activation of the AMH gene. Mol Endocrinol 17, 550-561.

Lundy T, P Smith, A O'Connell, NL Hudson, KP McNatty. 1999. Populations of granulosa cells in small follicles of the sheep ovary. J Reprod Fertil 115, 251-262. 
Manikkam M, TL Steckler, KB Welch, EK Inskeep, V Padmanabhan. 2006. Fetal programming: prenatal testosterone treatment leads to follicular persistence/luteal defects. Partial restoration of ovarian function by cyclic progesterone treatment. Endocrinology 147, 1997-2007.

Manikkam M, RC Thompson, C Herkimer, KB Welch, J Flak, FJ Karsch, V Padmanabhan. 2008. Developmental programming: impact of prenatal testosterone excess on pre- and postnatal gonadotropin regulation in sheep. Biol Reprod 78, 648-660.

Muruvi W, HM Picton, RG Rodway, IM Joyce. 2005. In vitro growth of oocytes from primordial follicles isolated from frozen-thawed lamb ovaries. Theriogenology 64, 1357-1370.

Ozanne SE. 2001. Metabolic programming in animals. Br Med Bull 60, 143-152.

Recabarren SE, T Sir-Petermann, A Lobos, E Codner, PP Rojas-Garcia, V Reyes. 2005 ${ }^{\mathrm{a}}$. Response to the gonadotropin releasing hormone agonist leuprolide in immature female sheep androgenized in utero. Biol Res 38, 235-44.

Recabarren SE, V Padmanabhan, E Codner, A Lobos, C Durán, M Vidal, DL Foster, T Sir-Petermann. 2005․ Postnatal consequences of altered insulin sensitivity in female sheep treated prenatally with testosterone. Am J Physiol Endocrinol Metab 289, 801-806.

Recabarren SE, PP Rojas-García, MP Recabarren, VH Alfaro, R Smith, V Padmanabhan, T Sir-Petermann. 2008. Prenatal testosterone excess reduces sperm count and motility. Endocrinology 149, 6444-6448.

Recabarren SE, PP Rojas-García, MP Recabarren, K Norambuena, T Sir-Petermann. 2009. Impacto de la exposición prenatal a testosterona sobre parámetros biométricos y endocrinos en ovejas recién nacidas. Arch Med Vet 41, 43-51.

Rojas-García PP, CI Abarca, CE Ulloa, VH Alfaro, MP Recabarren, DA Sandoval, T Sir-Petermann, SE Recabarren. 2006. Estudio preliminar de la histología ovárica en ovejas adultas con exposición prenatal a testosterona (EPT). XVII Reunión Anual Sociedad Chilena de Reproducción y Desarrollo. Reñaca, Chile.

Rojas-García PP, MP Recabarren, L Sarabia, J Schön, C Gabler, R Einspanier, M Maliqueo, T Sir-Petermann, R Rey, SE Recabarren. 2010. Prenatal testosterone excess alters Sertoli and germ cell number and testicular FSH receptor expression in rams. Am J Physiol Endocrinol Metab 299, E998-E1005.

Rosser C, C Herkimer, HN Sarma, SE Recabarren, A Dunaif, V Padmanabhan. 2003. Fetal programming: prenatal exposure to excess testosterone programs hyperinsulinemia. Biol Reprod 68 (Suppl 1), 293.

Sir-Petermann T, M Maliqueo, B Angel, HE Lara, F PerezBravo, SE Recabarren. 2002. Maternal serum androgens in pregnant women with polycystic ovarian syndrome: possible implications in prenatal androgenization. Human Reproduction 17, 2573-2579.

Sir-Petermann T, E Codner, M Maliqueo, B Echiburú, C Hitschfeld, N Crisosto, F Pérez-Bravo, SE Recabarren, F
Cassorla. 2006. Increased anti-müllerian hormone serum concentrations in prepubertal daughters of women with polycystic ovary syndrome (PCOS). J Clin Endocrinol Metab 91, 3105-3109.

Sir-Petermann T, N Crisosto. 2007. Polycystic ovary syndrome: a focus an anti-Müllerian hormone levels. Expert Rev Endocrinol Metab 2, 751-758.

Smith P, TL Steckler, A Veiga-Lopez, V Padmanabhan. 2009. Developmental programming: differential effects of prenatal testosterone and dihydrotestosterone on follicular recruitment, depletion of follicular reserve, and ovarian morphology in sheep. Biol Reprod 80, 726-736.

Steckler T, J Wang, FF Bartol, SK Roy, V Padmanabhan. 2005. Fetal programming: prenatal testosterone treatment causes intrauterine growth retardation, reduces ovarian reserve and increases ovarian follicular recruitment. Endocrinology 146, 3185-3193.

Steckler T, M Manikkam, EK Inskeep, V Padmanabhan. 2007. Developmental programming: follicular persistence in prenatal testosterone-treated sheep is not programmed by androgenic actions of testosterone. Endocrinology 148, 3532-3540.

Taieb J, M Grynberg, A Pierre, N Arouche, P Massart, C Bellsville, R Frydman, S Catteau-Jonard, R Franchin, JY Picard, N Josso, RA Rey, N di Clemente. 2011. FSH and its second messenger cAMP stimulate the transcription of human anti-Müllerian hormone in cultured granulosa cells. Mol Endocrinol 25, 645-655.

Visser J, F Jong, J Laven, A Themmen. 2006. Anti-Müllerian hormone: a new marker for ovarian function. Reproduction 131, 1-9.

Wang Y, S Chan, BK Tsang. 2002. Involvement of inhibitory nuclear factor- $\mathbf{} \mathrm{B}(\mathrm{NF}-\mathbf{\kappa} \mathrm{B})$-independent NFкB activation in the gonadotropic regulation of $\mathrm{X}$-linked inhibitor of apoptosis expression during ovarian follicular development in vitro. Endocrinology 143, 2732-2740.

Weenen C, JS Laven JS, AR Von Bergh, M Cranfield, NP Groome, JA Vissser, P Kramer, BC Fauser, AP Themmen. 2004. Anti-Mullerian hormone expression pattern in the human ovary: potential implications of initial and ciclic follicle recruitment. Mol Hum Reprod 10, 77-83.

West C, DL Foster, NP Evans, J Robinson, V Padmanabhan. 2001. Intra-follicular activin availability is altered in prenatally-androgenized lambs. J Clin Endocrinol Metab 84, 2951-2956.

Wood RI, DL Foster. 1998. Sexual differentiation of reproductive neuroendocrine function in the sheep. Rev Reprod 3, 130-140.

World Medical Association, American Physiological Society. 2002. Guiding principles for research involving animals and human beings. Am J Physiol Regul Integr Comp Physiol 283, R281-R283.

Xiao CW, K Ash, BK Tsang. 2001. Nuclear factor-B-mediated $\mathrm{X}$-linked inhibitor of apoptosis protein expression prevents rat granulosa cells from tumor necrosis factorB-induced apoptosis. Endocrinology 142, 557-563. 
